\title{
Perilaku menyimpang masyarakat penjudi merpati di Surabaya
}

\section{Deviant behaviour of pigeon gamblers in Surabaya}

\author{
Agung Septanto \\ Departemen Sosiologi, Fakultas Ilmu Sosial dan Ilmu Politik, Universitas Airlangga \\ Surabaya, 60286, Jawa Timur, Indonesia \\ E-mail: agung.septanto-12@fisip.unair.ac.id
}

\begin{abstract}
Abstrak
Judi merpati adalah judi dengan sarana burung yang dilombakan untuk mengadu kecepatan terbang merpati hingga sampai di garis finish yang telah dipersiapkan dan ditentukan oleh panitia "adu doro" (adu merpati). Di Surabaya kegiatan "adu doro" masih sering terlihat eksistensinya. Walaupun Surabaya termasuk kota besar, akan tetapi kegiatan "adu merpati" hanya dilakukan pada waktu tertentu yaitu hari Minggu atau hari libur. Burung merpati sebelum mengikuti lomba harus dilatih terlebih dahulu, latihannya dilakukan setiap sore hari agar "merpati" nya bisa lebih peka daya jelajahnya. Studi ini menggunakan metode kualitatif. Teori yang digunakan untuk menganalisis perjudian merpati yaitu teori asosiasi diferensial Edwin H Shuterland. Penelitian ini dilakukan di Kelurahan Banyu Urip Surabaya. Metode yang digunakan untuk mengumpulkan data yaitu menggunakan wawancara mendalam (Indepth interview) dengan informan penelitian. Hasil penelitian ini menunjukan bahwa perilaku menyimpang masyarakat penjudi merpati di Banyu Urip Surabaya, menjelaskan di satu sisi adanya judi merpati dianggap sebagai suatu hal yang biasa, karena masyarakat melihat judi merpati sebagai sebuah hiburan. Namun di sisi lain masyarakat menganggap judi merpati sebagai suatu permasalahan sendiri, karena mengganggu ketertiban dan kenyamanan di daerah sekitar adu merpati dilakukan.
\end{abstract}

Kata Kunci: judi merpati; taruhan; perilaku menyimpang; kontrol sosial

\begin{abstract}
Gambling pigeon is a gambling with the means of birds that are in the competition to pit the speed flying pigeons until the finish line that has been prepared and determined by the Committee "pigeons". In Surabaya activities "Adu Doro" is still often seen its existence. Although Surabaya is a big city, but the "Pigeon Shootout" is performed only a certain time that is Sunday or public holidays. "Pigeon" or pigeons before the race must be trained first, the exercises are done every afternoon so that the "pigeon" can be more sensitive to the explore. This study employed qualitative method. The theory used to analyse pigeon gambling uses theory of differential association by Edwin H Shuterland. This research was conducted in Banyu Urip village Surabaya. The method used to collect data is to use in-depth interviews with the research informants. The results showed that the aberrant behavior of the community of "penjudi merpati" in Banyu Urip Surabaya, explained on the one hand the presence of pigeon gambling is regarded as a normal thing, because the public sees pigeon gambling as an entertainment. But on the other hand consider gambling pigeons as a problem themselves, because it interferes with order and comfort in the area around the pigeon.
\end{abstract}

Keywords: pigeon gambling; bets; deviant behaviour; social control

\section{Pendahuluan}

Di era kontemporer seperti sekarang ini berbagai macam jenis perjudian banyak ditemukan di tingkat lapisan masyarakat. Mulai dari jenis perjudian modern seperti tebak skor bola yang melibatkan kalangan investor dan operasionalnya yang menggunakan teknologi informasi internet (LaPlante 2009; Binde et al. 2017) sampai perjudian tradisional seperti judi togel, sabung ayam, adu kambing, judi balap hewan peliharan dan lain- lain (Sallaz 2008; Curnow 2012). Secara istilah perjudian adalah pertaruhan dengan sengaja yaitu mempertaruhkan satu nilai atau sesuatu yang dianggap bernilai dengan menyadari adanya resiko dan harapan-harapan tentu ada suatu peristiwa-peristiwa dalam setiap permainan, pertandingan, perlombaan dan kejadian-kejadian yang tidak atau belum pasti hasilnya (Kartono 2009).

Perjudian akhirnya secara resmi atau secara hukum dilarang oleh pemerintah dan dianggap sebagai suatu hukum tindak pidana atau kejahatan sebagaimana yang sudah tertuang dalam UU. No.7 Tahun 1974 tentang penertiban perjudian, yang kemudian dipertegas pelaksanaanya dalam pasal 101 dan 541 
KUHP, PP No. 9 Tahun 1981 dan Instruksi Pangkop Kamtib No. Ins 004/KPOKAM/ IV/1971. Hal ini dilakukan pemerintah dengan alasan bahwa perjudian dapat merusak sendi-sendi ekonomi dan moral bangsa (Widiatedja, 2018). Perjudian diramalkan akan melahirkan generasi-generasi penerus bangsa yang tidak berkualitas, pasrah terhadap nasib dan tidak ingin maju (Simanjuntak 1981).

Judi merpati adalah judi dengan sarana burung yang dilombakan untuk mengadu kecepatan terbang banyak merpati untuk sampai garis finish yang telah dipersiapkan dan ditentukan oleh panitia "adu doro". Di Surabaya kegiatan "adu doro" terlihat masih sering terlihat eksistensinya. Kegiatan judi merpati biasanya dilakukan setiap hari Minggu sore, dengan adanya "adu doro" tersebut dapat dipastikan ada kegiatan perjudian yang di mana masing- masing orang menjagokan "doro" nya sesuai pilihanya sendiri yang sedang di adu, apabila pilihan "doro" yang diadunya menang maka orang tersebut mendapatkan hasil uang taruhan. Di mana perjudian yang seharusnya diberantas oleh aparat kepolisian tapi nyatanya tidak ada sanksi apa-apa bagi orang yang melakukan judi "adu doro". Berdasarkan data yang di peroleh di wilayah hukum Polrestabes Surabaya, masih banyak dijumpai tempat-tempat perjudian, seperti judi burung merpati "adu doro" di Banyu Urip, Sidotopo, Pemakaman Kembang Kuning yang menjadi titik berkumpul kalangan orang-orang penjudi "adu doro"terutama di daerah Banyu Urip. Kegiatan "adu doro" sendiri sudah melibatkan sebagian anakanak dalam kegiatannya, yang seharusnya anak belajar dan bermain sesuai dengan umurnya tapi anak sudah diajarkan tata cara bermain "adu doro" tersebut.

Selain judi yang dilakukan di Banyu Urip perjudian merpati juga di lakukan di daerah Karang Asem yang pada hari Rabu (1/8/2017). Anggota Polsek Tambaksari melakukan penggerebekan arena judi merpati sekitar pukul 15.00 WIB. Sedikitnya 40 orang yang diduga terlibat judi merpati diciduk dan dibawa ke Mapolrestabes Surabaya beserta barang bukti burung merpati, keranjang burung dan alat kentungan. Ketika dilakukannya penggerebekan judi merpati terbesar di Surabaya itu terjadi karena adanya aduan atau informasi dari masyarakat yang resah karena tempat tinggalnya digelar judi yaitu di antaranya judi dadu, judi merpati, judi adu ayam, hingga judi togel. Selain itu judi merpati juga terjadi di daerah Ploso Surabaya yang di obrak-abrik oleh petugas gabungan yang melakukan operasi. Dalam hal ini jajaran Koramil, Pol PP, dan Polisi menghancurkan pegupon yang terdiri di area Ploso tersebut. Dari hasil razia judi merpati di Ploso Timur RW X, di Kelurahan Ploso memberikan sanksi merobohkan setidaknya 11 titik pagupon dan setidaknya ada 4 buah pagupon yang dirobohkan oleh pemiliknya sendiri.

Menurut Narwoko \& Suyanto (2004), perilaku menyimpang menyiratkan kesan, meskipun tidak ada masyarakat yang seluruh warganya dapat mentaati dengan patuh seluruh aturan norma sosial yang berlaku, tetapi apabila terjadi pelanggaran yang dilakukan oleh seseorang, maka hal itu dianggap telah mencoreng aib sendiri, keluarga maupun komunitas besarnya. Selain itu meresahkan warga sekitar lokasi arena perjudian merpati, pada umumnya para pemain burung merpati bukan masyarakat sekitar namun masyarakat pendatang atau daerah lain. Hal ini secara membuat kondisi keamanan daerah sekitar mengalami keresahan selain karena judi doro, yang di khawatirkan orang tua jika anak- anak kecil sekitar lokasi tersebut terkena dampaknya, seperti disuruh melepaskan burung merpati ataupun menjaga bekupon merpati dengan embel-embel di kasih uang.Pemerintah dengan hal ini berusaha keras untuk menekan atau mengurangi penyebaran dan memberantas tindak perjudian pada masyarakat lapisan bawah, namun fakta yang terjadi di lapangan menunjukan bahwa lapisan bawah semakin meningkat dan berkembang (Nooteboom 2015). Hal ini terjadi lantanan masyarakat lapisan bawah memandang judi memiliki nilai positif bagi dirinya (Beckert \& Lutter 2013; Rocheleau et al. 2020).

Seperti Menurut Furnham dan Argyle (1998:116-117) mengungkapkan bahwa perjudian yang marak tidak hanya diikuti oleh penjudi yang patologis tetapi juga penjudi non-patologis. Hal ini dapat dilihat dari jutaan orang yang setiap harinya bermain judi, baik mereka yang berasal dari status sosial ekonomi yang tinggi maupun yang rendah. Mereka bermain judi dalam berbagai macam bentuk permainan, tetapi hal ini tidak lantas dapat dikatakan bahwa mereka semua itu adalah pecandu atau penjudi patologis (Cheung 2016). 
Adapun menurut Binde (2013), terdapat beberapa penyebab yang dapat mendorong seseorang melakukan tindak perjudian, diantaranya yaitu: a) Kekurangan ekonomi masyarakat dengan semacam ini secara sadar membutuhkan rangsangan untuk melakukan perbaikan diri terhadap dalam hal kondisi ekonomi; b) Cara cepat atau mudah sekali mendapatkan uang; c) Kesempatan mendapatkan uang lebih besar dari pada kerja; d) Mengadu nasib; e) Mendapatkan sebagian dari penghasilan tambahan, dan lain sebagainya.

Akibat-akibat seseorang yang melakukan perjudian menurut Menurut Kartono (2009: 81-84), kebiasaan berjudi mengkondisikan mental individu menjadi ceroboh, malas, mudah berspekulasi dan cepat mengambil resiko tanpa pertimbangan. Ekses lebih lanjut antara lain 1) Mendorong orang untuk melakukan tindakan upaya penggelapan uang seperti di kantor/dinas; 2) Energi dan pikiran jadi berkurang, karena sehari-harinya didera oleh nafsu judi dan kerakusan ingin menang dalam jangka waktu pendek; 3) Badan menjadi lesu dan sakit-sakitan, dikarenakan kurang tidur, serta selalu dalam keadaan tegang tidak imbang; 4) Pikiran menjadi kacau, sebab selalu digoda oleh harapan-harapan yang tidak menentu; 5) Pekerjaan menjadi telantar, karena segenap minatnya tercurah pada keasyikan berjudi; 6) Anak istri dan rumah tangga sudah tidak lagi diperhatikan selayaknya; 7) Di dalam hatinya jadi mudah rapuh, mudah tersinggung dan cepat tersulut marah, bahkan sering eksplosif meledakledak secara membabi buta; 8) Mentalnya terganggu dan pada akhirnya menjadi sakit, sedangkan kepribadiannya labil 9) Orang selalu lalu terdorong dengan suatu keinginan melakukan tindak kriminal, guna mencari modal untuk mencari pemuas nafsu judinya secara tidak dapat terkendali. Setiap orang mulai berani melakukan tindak perbuatan seperti, mencuri, berbohong, dan menipu, mencopet, menodong, merampok, membunuh, teruntuk lagi mendapatkan tambahan modal guna berjudi. Akibatnya, jumlah angka kriminalitas naik dengan drastis dan setiap keamanan kota di setiap daerah-daerah pinggiran menjadi sangat rawan dan tidak aman; 10) Ekonomi rakyat saat ini mengalami kegoncangan- kegoncangan sehingga membuat setiap orang akan bersikap spekulatif dan untung-untungan, kurang serius dalam mengawali karir usaha kerjanya; 11) Diseret oleh nafsu judi yang berl arut-larut, kurang iman kepada Tuhan, sehingga mudah tergoda melakukan tindakan asusila jelas, bahwa rakyat kecillah yang paling menderita ditimpa oleh ekses-ekses judi.

Berbagai studi mengenai adu merpati telah banyak di teliti seperti yang telah dilakukan oleh Hera pada tahun 2017, yang terjadi di wilayah daerah Kelurahan Kapas Madya Baru Kecamatan Tambaksari kota Surabaya Studi mengenai tentang keterlibatan anak dalam kegiatan adu doro. Dari hasil studi penelitian yang dilakukan menunjukan, bahwa setiap anak terlibat dalam kegiatan adu doro mayoritas bukan karena keturunan tapi karena proses belajar yang melihat teman sebayanya juga mengikuti kegiatan adu doro. Anak terlibat dalam kegiatan adu doro karena terjadi adanya dorongan dari diri sendiri, teman sebaya dan lingkungan. Keterlibatan anak dapat terjadi karena kontrol internal dan kontrol eksternal yang lemah sehingga tidak dapat sanksi yang diberikan pada anak yang terlibat dalam kegiatan adu doro.

\section{Metode Penelitian}

Penelitian ini menggunakan tipe penelitian deskriptif, di mana tipe penelitian deskriptif adalah penelitian yang dimaksudkan memberikan dan menginterpretasikan objek sesuai dengan apa adanya (Best 1981). Dan menggunakan Dari paradigma definisi sosial ini memandang bahwa ilmu sosial sebagai analisis terhadap socially meaningful action melalui pengamatan langsung dan terperinci terhadap pelaku sosial yang bersangkutan menciptakan dan memelihara atau mengelola dunia sosial mereka.

Informan yang diwawancarai yaitu penduduk Banyu Urip yang melakukan adu doro. Subjek ini adalah informan yang tepat untuk menggambarkan penelitian. Data diperoleh dari data primer berupa wawancara mendalam dengan para penjudi merpati. Data sekunder diambil dari berbagai literatur yang relevan dengan topik yang dikaji. Data yang diperoleh dianalisis dengan menggunakan teori asosiasi diferensial Edwin Sutherland. 


\section{Hasil dan Pembahasan}

Menurut "Asosiasi Diferensial”, penyimpangan adalah konsekuensi dari kemahiran dan tindakan yang dipelajari dari norma-norma yang menyimpang, terutama dari kegiatan atau di antara teman-teman sebaya yang menyimpang (Shuterland 2011). Teori asosiasi deferensial digunakan untuk mengetahui adanya kalangan judi merpati "adu doro" di Kecamatan Banyu Urip kota Surabaya. Teori perilaku menyimpang dipelajari dengan melibatkan semua mekanisme yang terlibat dalam proses belajar. Dengan ini mengungkapkan bahwa "kejahatan merupakan ekspresi dari nilai-nilai kebutuhan umum karena perilaku kriminal merupakan ekpresi nilai dan kebutuhan yang sama." Jadi orang yang melakukan penyimpangan karena adanya depresi, keinginan diri sendiri, status atau karena materi (Aasved 2003; Kristiansen \& Trabjerg 2017; Nicoll 2019). Jika ibarat dikaitkan dengan penelitian ini, bagaimana perilaku menyimpang masyarakat penjudi merpati di Banyu Urip Surabaya, maka suatu kegiatan yang dilakukan oleh orang-orang itu berasal dari proses belajar yang dilihat oleh orang-orang tersebut, dengan melihat secara terus-menerus maka secara tidak langsung maka seseorang itu juga akan belajar melakukan dengan apa yang dia lihat. Proses belajar dapat dilakukan oleh anak berdasarkan teori ini lebih menjurus bahwa faktor utama dari proses belajar seseorang adalah lingkungan.

Adapun teori asosiasi diferensial memiliki 9 proposisi: a) Perilaku menyimpang adalah hasil dari proses belajar yang dipelajari, berarti jika perilaku menyimpang bukan hasil dari keturunan atau diwariskan dari orang tua; b) Perilaku menyimpang dapat dipelajari semisal seseorang berinteraksi dengan orang-orang yang ada di sekitarnya sehingga komunikasi nantinya dilakukan secara intim; c) Pengaruh dasar utamanya adalah dari suatu kelompok- kelompok personal yang intens. Dan media massa, seperti televisi, koran, majalah juga memberikan dampak pengaruh penuh terhadap pembentukan kepribadian walaupun hanya sekundernya. d) Hal-hal yang dipelajari dalam proses perilaku menyimpang adalah teknis-teknis penyimpangan dan adanya motif, dorongan, rasionalisasi dari lingkungan dan sikap- sikap menyimpang; e) Adanya motif dan dorongan untuk berperilaku menyimpang itu dipelajari dari pengertian-pengertian yang baik dan tidak baik menurut mereka. Sehingga lingkungan yang menjadi tempat sosialisasi memberikan definisi-definisi norma dan nilai terkadang menurut kita baik belum tentu orang lain melihatnya baik; f) Bila seseorang tersebut akan mengalami penyimpangan bisa dikarenakan melanggar normayang lebih menguntungkan; g) Terbentuknya dari asosiasi diferensial itu sangat bervariasi tergantung dari frekuensi, durasi, prioritas dan intensitas; h) Proses bagaimana mempelajari penyimpangan perilaku melalui kelompok yang juga memiliki jenis pola-pola dan mekanisme tertentu. Ini berarti tidak ada proses yang lebih unik untuk memperoleh sesuatu cara berperilaku menyimpang. Walaupun setiap tingkah laku yang menyimpang merupakan ekspresi dari kebutuhan umum, perilaku menyimpang tidak dapat di beda-bedakan berdasarkan kebutuhan umum sehari-hari, karena perilaku menyimpang pun sebagai ekspresi dari nilai-nilai dan kebutuhan yang sama (Goode 2015; Cohen 2018).

Sebuah teori ini menjelaskan bagaimana penyimpangan itu terjadi melalui proses pembelajaran dimana Shuterland membagikan gagasan ke dalam sembilan proposisi yang merupakan rumusan atau poin-poin penting untuk menganalisis sebuah penyimpangan pejudi merpati. Proses penyimpangan penyimpangan penjudi merpati bukan didapatkan dari proses pewarisan sifat secara biologis, hal tersebut bisa didapatkan dari teman sekitar, dan semakin banyak waktunya dihabiskan untuk temannya dan lingkungan yang banyak mengikuti dan terlibat kegiatan judi merpati "adu doro" yang nantinya menyebabkan informan terdorong untuk lebih mengetahui dan mempelajari serta melakukan hal tersebut. Pembelajaran menjadi pemain atau pelaku terdapat dalam teori yang dikemukakan oleh Shuterland yaitu asosiasi deferensial membagi sembilan proposisi penting yaitu dasar sebuah perilaku menyimpang tidak diwariskan, maksudnya adalah perilaku meyimpang yang dilakukan oleh pelaku penjudi merpati bukan karena pewarisan sifat atau karena faktor keturunan dari orang tuanya. Hal ini diperkuat dengan beberapa informan bahwa salah satu faktor yang membuat informan mengikuti judi merpati "adu doro" yakni melalui faktor teman sebayanya.

Jika dikaitkan dengan teori asosiasi deferensial yang menganggap perilaku menyimpang penjudi merpati tidak diwariskan dari orang lain maka hal tersebut benar dari 5 informan yang menyatakan 
keterlibatannya dalam permainan judi merpati dipengaruhi dari teman sebayanya, diri sendiri dan lingkungan penjudi merpati. Lingkungan keluarga dalam mengetahui hal ini menganggap bahwa kegiatan judi merpati yang berada di Banyu Urip menganggap hanya sebagai ajang hiburan atau tontonan yang gratis, walaupun sesungguhnya keluarga menilai hal tersebut menyalahi aturan jika dicampurkan dengan judi, namun keluarga juga menginginkan agar anaknya tidak terjebak dalam kegiatan negatif. Akan tetapi informan kalah dorongan dari dirinya sendiri dan teman sebayanya serta kesenangan dan hiburan yang informan dapatkan menyebabkan informan tetap mengikuti kegiatan tersebut.

Berdasarkan wawancara dengan informan, awal pembelajaran tentang kegiatan "adu doro" didapatkan dari teman-teman yang selalu berkumpul. Manusia adalah mahluk individu tapi bukan hanya itu, manusia juga mahluk sosial yang memelihara eksistensinya dengan berinteraksi dengan manusia lainnya dalam bermasyarakat. Karena tidak manusia yang bisa hidup tanpa bantuan dari orang lain dan tanpa berhubungan atau berinteraksi dengan sesamanya. Sehingga tidak secara langsung berhubungan dengan orang lain atau berinteraksi secara intens juga akan membentuk kepribadian. Seperti pepatah "jika kita bergaul dengan pengusaha maka akan ikut kaya, tapi jika kita bergaul dengan pencuri maka kita akan ikut menjadi residivis". Seperti itulah lingkungan dan pergaulan yang menyimpang maka pengikutnya juga akan menyimpang juga (Clark, 1962; Malizia, 2018), sama dengan penelitian ini apabila sering berinteraksi dengan kalangan penjudi merpati maka tidak menutup kemungkinan mendorong informan untuk mengikuti kegiatan adu doro.

Perilaku menyimpang akan ada karena manusia menyerap informasi dan motivasi dari orang- orang terdekat di sekitar, pada proposisi kedua Shuterland percaya bahwa setiap orang-orang bisa untuk melakukan tindakan menyimpang jika selalu dihadapkan dengan perilaku menyimpang tersebut. Berawal ketika informan berkumpul dan bergaul dengan teman lainya yang mengikuti kegiatan "adu doro" dengan adanya memperkuat bahwa perilaku menyimpang dipelajari dalam interaksi yang intens dengan orang lain di dalam komunikasi. Kelompok adalah sekumpulan orang yang mempunyai tujuan bersama yang berinteraksi satu sama lain untuk mencapai tujuan bersama, mengenal satu sama lain dan memandang mereka bagian dari kelompok tersebut (Mulyana 2005). Menurut Informan dan temannya memang tidak secara resmi komunikasi dengan teman- temanya intens maka hal ini bisa disebut dengan kelompok.

Dalam hal ini komunikasi antara informan dan teman-teman bermainya telah terjalin sejak lama, dan hubungan antara informan dan teman-temannya telah akrab satu sama lain sudah saling percaya, sehingga pada saat berkumpul temannya pun saling membicarakan tentang perjudian adu merpati, dan selalu memberikan informasi secara terus menerus membuat informan mulai tertarik apalagi adanya iming- iming tidak lama pasti akan terpikat dengan ajakan teman yang lain mengikuti kegiatan judi merpati di lingkungan Banyu Urip.

\section{Simpulan}

Studi ini menyimpulkan bahwa pada kalangan penjudi merpati di Surabaya, di satu sisi adanya judi merpati dianggap sebagai suatu hal yang biasa, karena masyarakat melihat judi merpati sebagai sebuah hiburan. Namun di sisi lain menganggap judi merpati sebagai suatu permasalahan tersendiri, karena mengganggu ketertiban dan kenyamanan di daerah sekitar adu merpati dilakukan.

Perilaku menyimpang kegiatan adu merpati di Banyu Urip Surabaya awalnya hanya sebagai ajang permainan balap keindahan terbang, namun lambat laun mengakibatkan sebuah proses perubahan yang merambah dengan menggunakan uang taruhan sebagai media bentuk permainan burung merpati untuk mengetahui kecepatan dan ketangkasan burung. Permasalahan yang timbul dari adanya judi merpati di masyarakat Banyu Urip Surabaya seperti perputaran uang judi (ekonomi) dan menyumbang serta meningkatnya tindak kekerasan dalam rumah tangga maupun sosial. 


\section{Daftar Pustaka}

Aasved M (2003) The Sociology of Gambling: Volume II. Charles C Thomas Publisher.

Beckert J, Lutter M (2013) Why the poor play the lottery: Sociological approaches to explaining classbased lottery play. Sociology 47 (6):1152-1170.

Binde P (2013) Why people gamble: a model with five motivational dimensions. International Gambling Studies 13 (1):81-97. doi:10.1080/14459795.2012.712150

Binde P, Romild U, Volberg RA (2017) Forms of gambling, gambling involvement and problem gambling: evidence from a Swedish population survey. International Gambling Studies 17 (3):490-507. doi:10.1080/14459795.2017.1360928

Cheung NW (2016) Social strain, self-control, and juvenile gambling pathology: Evidence from Chinese adolescents. Youth \& Society 48 (1):77-100.

Clark JP (1962) Socio-economic class and area as correlates of illegal behavior among juveniles. American Sociological Review 27 (6):826-834.

Cohen AK (2018) The Sociology of the Deviant Act: Anomie Theory. In Deviance and Liberty (pp. 44-53). Routledge.

Curnow J (2012) Gambling in Flores, Indonesia: Not such risky business. The Australian Journal of Anthropology 23 (1):101-116.

Goode E (2015) Deviant Behavior. Routledge.

Kartono K (2011) Patologi Sosial Jilid I. Jakarta: Raja Grafindo Persada Media.

Kristiansen S \& Trabjerg CM (2017) Legal gambling availability and youth gambling behaviour: A qualitative longitudinal study. International Journal of Social Welfare 26 (3):218-229.

LaPlante DA (2009) Sitting at the Virtual Poker Table: A Prospective Epidemiological Study of Actual Internet Poker Gambling Behavior, 25 Computers in Human Behavior 729.

Malizia N (2018) Boredom and social deviant behavior: An empirical study. Advances in Applied Sociology 8 (02):174.

Mulyana D (2005) Ilmu Komunikasi Suatu Pengantar. Bandung: Remaja Rosda karya.

Nicoll FJ (2019) Gambling in Everyday Life: Spaces, Moments and Products of Enjoyment. Routledge.

Nooteboom G (2015) Living dangerously: Oplosan, gambling, and competition as everyday risk taking in Java and East Kalimantan Indonesia. Disaster Prevention and Management 24(4):523538.

Narwoko DJ \& Suyanto B (2010) Sosiologi: Teks Pengantar dan Terapan. Jakarta: Kencana.

Rocheleau GC, Dennison CR, Finkeldey JG, Reiber MF (2020) Social class differences in the relationships between problem gambling and deviant behavior. Criminal Justice Studies, 1-20.

Sallaz JJ (2008) Deep plays: A comparative ethnography of gambling contests in two postcolonies. Ethnography 9 (1):5-33.

Simanjuntak B (1981) Pengantar Kriminologi dan Patologi. Bandung: Tasrito. Budi T (2011) Sosiologi: Perilaku Menyimpang. Surabaya: PT. Revka Petra.

Widiatedja IGNP (2018) Can Indonesia invoke public morals exception under the World Trade Organization (WTO) for prohibiting cross-border gambling? Yustisia Jurnal Hukum 7 (2):261279. 